\title{
Planejamento Estratégico de um Distrito Industrial Não Poluente e Residencial no Município de Presidente Prudente - SP
}

Strategical Planning of a Pollutant Non-Industrial District and Residential in the City of Presidente Prudente - SP

Planificación Estratégica de un Distrito Industrial No Contaminante y Hostales en el Municipio de Presidente Prudente - SP

Marcelo Yukio Takigawa Técnico em Agrimensura, ETEC - Presidente Prudente, Brasil. marceloyukito@gmail.com

Monica Kurak Lombardi Professor Mestre, ETEC e FATEC Presidente Prudente, Brasil. monikakurak@gmail.com

Bruno Sandrin Nascimento Geógrafo e Técnico em Agrimensura, Brasil nascimento.bruno92@yahoo.com 


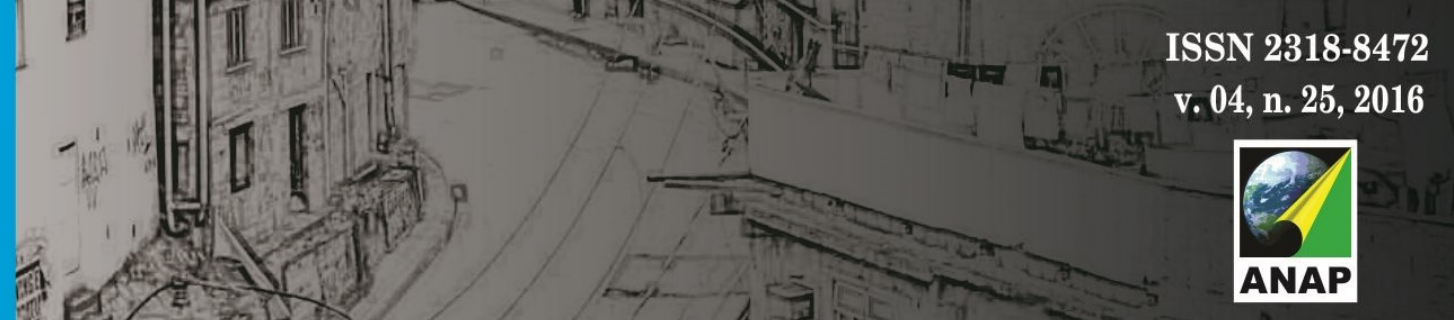

Revista Nacional de Gerenciamento de Cidades

\section{INTRODUÇÃO}

A atividade industrial é importante por sua capacidade de dinamizar outros setores econômicos. Sua inter-relação com diversas atividades é responsável pela geração de emprego e renda, assim como estimular o desenvolvimento tecnológico, social e econômico do local em que está instalada. É considerada o motor da economia e fomentadora do desenvolvimento municipal.

O distrito industrial difere do conceito de Zona Industrial e Área Industrial, por ser uma área definida pelo Poder Público como o melhor local para sua implantação e instalação sendo planejada de tal forma para ocupação exclusiva de atividades industriais. Para atrair indústrias para a área escolhida, mais importante que a isenção de impostos e taxas, é o planejamento da infraestrutura, existência de mão de obra, facilidades de acesso e distribuição de insumos e mercadorias.

O planejamento estratégico de um novo Distrito Industrial deve ser alvo de um cuidadoso estudo da área, além da consulta a órgãos públicos, análise da potencialidade da região e também contar, em todo o seu processo, com a participação da sociedade civil e métodos para monitoramento e acompanhamento do seu desenvolvimento.

Para a escolha da área devem ser observadas as exigências legais e técnicas da legislação pertinente (Federal, Estadual e Municipal). No âmbito federal têm-se as Diretrizes gerais da política urbana, Sistema Nacional de Viação, Estatuto das Cidades e Legislação Ambiental (CONAMA). Para aprovação Estadual se faz necessário Licenças de Prévia e de Instalação com manifestação da CETESB e GRAPROHAB (por se tratar de loteamento misto), assim como avaliação de impacto ambiental conforme resolução da CONAMA. Na legislação municipal o parâmetro é o Plano Diretor, a Lei do Sistema Viário e a Lei de Uso e Parcelamento do Solo.

Apesar das vantagens apresentadas, uma área com infraestrutura capaz de receber instalações industriais possui características próprias que devem ser analisadas tais como: impacto à população urbana, direção do vento, limitação espacial e desenvolvimento das atividades na área loteada, incompatibilidade com a vizinhança, dificuldade de desenvolvimento, custos com a implantação da infraestrutura em áreas distante da malha urbana consolidada, dificuldades no deslocamento de mão de obra, aceitação do local pelos empresários.

Também é importante a realização de estudo para identificar a potencialidade econômica para a implantação de uma área industrial no município para definir o tamanho do loteamento e planejamento de implantação. A construção pode ser realizada em etapas, conforme a demanda por áreas for aumentando, para desestimular a ociosidade ao longo do tempo e o parcelamento dos investimentos em obras de infraestrutura. Necessário, nesse caso, a reserva de área para sua ampliação constante no projeto a ser aprovado.

Durante o processo de criação e implantação a Câmara Municipal deve providenciar o projeto e a aprovação das leis para a criação do distrito industrial, incentivos fiscais para implantação de indústrias e desenvolvimento econômico municipal.

Após a estruturação do empreendimento, é importante a divulgação voltada à classe empresarial, com a elaboração de um plano de marketing, que facilite a adesão e promoção do novo Distrito Industrial. 


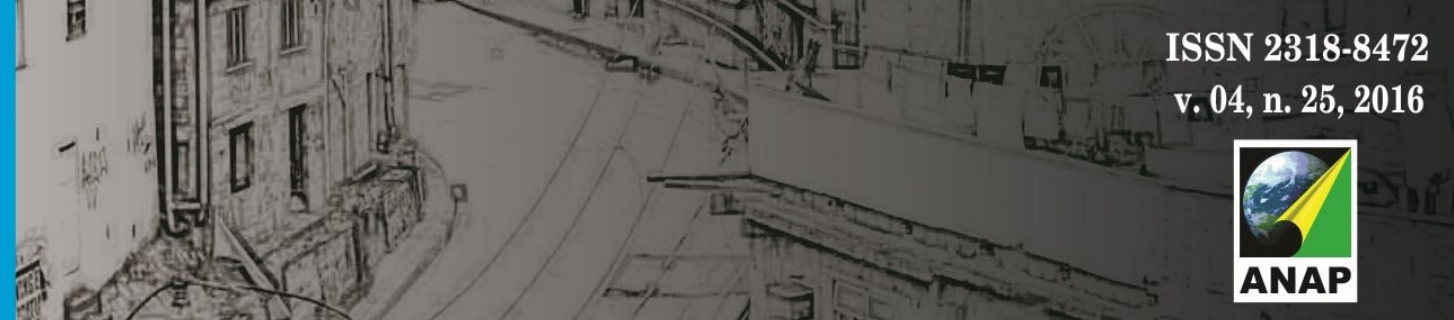

Gerenciamento de Cidades

disseminados na gestão ambiental brasileira, conforme manual da CETESB. O anexo 1 da Resolução CONAMA $n^{\circ}$ 237/1997 ficou estabelecido os principais tipos de empreendimentos sujeitos ao licenciamento ambiental, sendo incluído nisso como atividades diversas o Distrito ou Pólo Industrial e suas respectivas atividades inerentes.

Verificando a Deliberação CONSEMA Normativa 01/2014 e site da Secretaria do Meio Ambiente, verificou-se que o Município de Presidente Prudente não possui as qualificações necessárias para emissão de Licenciamento Ambiental Municipal, sendo que,no site do órgão é possível, podemos visualizar municípios considerados de menor porte com tal atribuição.

O Estudo de Impacto Ambiental e respectivo Relatório de Impacto Ambiental (EIA/RIMA) é um documento técnico-científico composto pelos seguintes elementos: Diagnóstico ambiental dos meios físico, biótico e socioeconômico; Análise dos impactos ambientais do projeto e de suas alternativas; Definição das medidas mitigadoras dos impactos negativos e Programas de Acompanhamento e Monitoramento. O RIMA é um documento público que reflete as informações e conclusões do EIA e é apresentado de forma objetiva e adequada a compreensão de toda a população. Nessa etapa são realizadas audiências públicas para que a comunidade interessada e/ou afetada pelo empreendimento seja consultada.

Acessado o Plano Diretor do Município de Presidente Prudente, pode-se destacar o seu objetivo de conciliar a preservação e proteção do meio ambiente com o uso e ocupação do solo e o desenvolvimento econômico, controlar a distribuição espacial das atividades e controle da política do sistema viário.

A lei de zoneamento e ocupação do solo municipal contempla o estudo de impacto da vizinhança na aprovação de empreendimentos, classificação hierárquica de usos, índices urbanísticos e os limites das zonas de preservação.

A lei do sistema viário disciplina as vias que compõem o sistema assim como aquelas que vierem a ser implantadas em futuros empreendimentos. Também nota-se uma preocupação com as áreas de preservação, rampas, declividade, classificação das mesmas e larguras das pistas de rolamento.

Para evitar contratempos, levantamentos e trabalhos errôneos e consequentemente a coleta de dados desnecessários e duplicados, é necessário um planejamento prévio da escolha da área a ser adotada como ideal para o empreendimento. Planejar pode ser considerada como um conjunto de decisões a serem tomadas previamente para atingir um resultado final satisfatório. CHIAVENATO (2004) defende o planejamento como uma base para as realizações das demais ações futuras, determinando os objetivos e planos para atingi-los da melhor maneira possível.

\section{VIABILIDADE E ESTUDO DA ÁREA}

Segundo o DEPECON (Departamento de Pesquisas e Estudos Econômicos) da FIESP, reunindo dados do IBGE de 2013, a região de Presidente Prudente ocupa a 37a posição de 39 regiões do PIB per capita do Estado de São Paulo, sendo a indústria e o setor de construção responsáveis por $21,3 \%$ desse total. $O$ estudo também aponta, conforme dados do RAIS (Relação Anual de Informações) do Ministério do Trabalho, que o setor era responsável por 23,7\% dos empregos formais e 5,9\% dos estabelecimentos era formado pela indústria de transformação e em sua grande maioria de pequeno porte com até 99 empregados formais. 


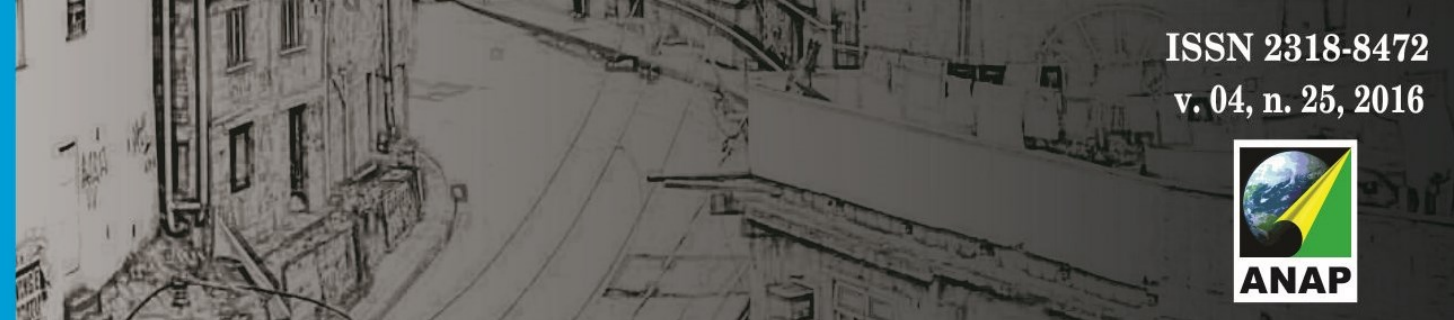

Gerenciamento de Cidades

A incorporação de novos consumidores de tecnologia devido às políticas sociais e aumento da renda média, demandaram maior geração de capital, esta sendo fruto de políticas de desenvolvimento industrial que gera divisas e empregos, estimulando os diversos setores econômicos e o mercado interno.

O setor de serviços, tão atuante, dinâmico e preponderante na economia brasileira, mostra-se atrelado ao setor da indústria de transformação. Atualmente nota-se a diminuição da produção nacional de insumos e aumento nas importações de produtos industrializados, gerando déficits na balança comercial e diminuindo a força, estímulo e produção interno. Para a importação dos produtos o país necessita de moeda estrangeira que provêm das receitas de exportação sejam elas provenientes da venda de produtos primários (muitas vezes assolados por intempéries climáticas sazonais) e produtos industriais (com maior valor agregado). A perda da competitividade deve-se também a política cambial e o elevado custo Brasil, tão afamado e divulgado nas mídias, porém sem medidas corretivas de que carece. Soma-se a isso a pouca diversidade do setor apresentada no país, restringindo a cadeia produtiva brasileira.

O município de Presidente Prudente conta atualmente com zoneamentos industriais em diversos pontos da cidade, sendo localizados no Conjunto Habitacional Brasil Novo, Conjunto Habitacional Mario Amato, uma faixa margeando a Rodovia Raposo Tavares e setor sudeste da cidade. Visualizando pelo Google Maps pode-se notar que a ocupação primordial da faixa localizada às margens da Rodovia é o de grandes galpões comerciais e não o de indústrias transformadoras. Nesta área estão localizados também alguns bairros considerados como de médio alto padrão, incutindo em conflitos de interesse quanto a locação de indústrias de transformação no local. Nas outras áreas, os espaços ocupados pelas indústrias apresentam um bom adensamento, e no novo distrito (que conta com 78 lotes) foram entregues, até janeiro de 2016, 32 lotes para as empresas, evidenciando o interesse do setor em se instalarem no município.

Estudos realizados por PULIDO (2011) na região do Distrito Industrial Antonio Crepaldi revelaram que as empresas ali instaladas geravam grande quantidade de resíduos e pela pedologia e declividade do terreno, poderiam levar a contaminações tanto do solo quanto do lençol freático se atitudes não forem tomadas no sentido de minimizar os impactos ambientais.

Existe no local o aterro sanitário (muitas vezes criticado e sem vislumbre de solução, apesar das críticas do Ministério Público) e visualiza-se nas proximidades do local a retirada de terras. Tal estudo pode ser estendido às outras áreas classificadas como zonas industriais por serem produtoras de resíduos sólidos e líquidos, além de estarem próximas a grandes adensamentos urbanos e gerarem tanto poluição sonora quanto atmosférica, além do aumento no tráfego de veículos pesados.

Empreendimentos desse tipo podem levar a desvalorização dos imóveis mais próximos impactando negativamente o mercado imobiliário. $O$ endividamento da população brasileira também reflete na retração do consumo de imóveis novos e a diminuição do crédito concedido pelos bancos, fazendo com que imóveis fiquem ociosos.

Observa-se a expansão urbana do município no sentido oeste e norte devido a fatores políticos, econômicos e físicos, como as características do relevo, sendo que a parte leste sofre com declives acentuados. (SUDO, 1996). Outro fator a ser levado em conta para a escolha de um novo distrito industrial é a quantidade de calor que tal empreendimento gera afetando a temperatura média na região. 


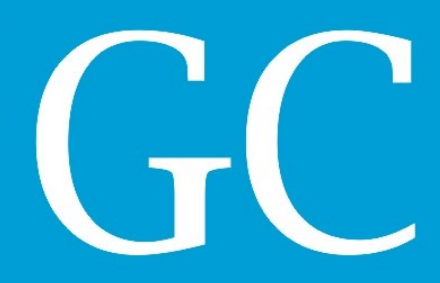

Revista Nacional de

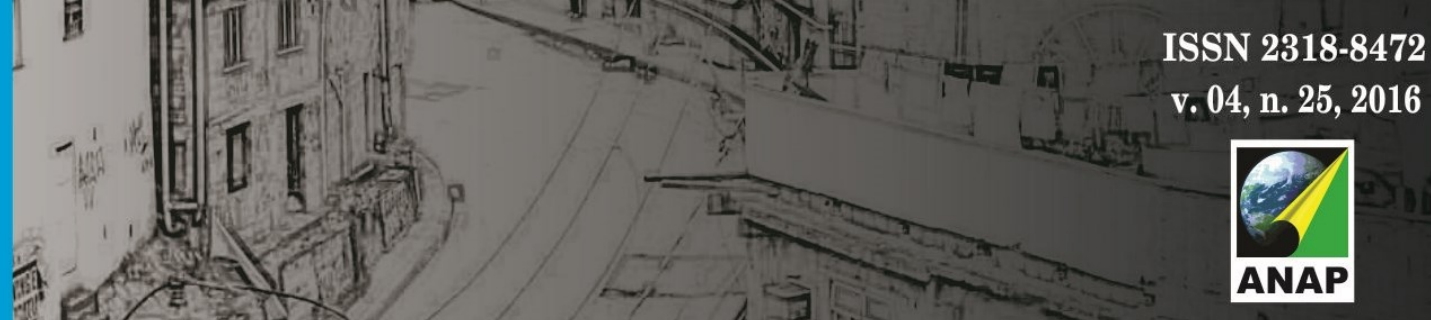

Gerenciamento de Cidades

National Journal of Cities Management

Para a escolha de um local adequado para a implantação do distrito industrial pode-se utilizar programas para a geração de curvas de nível, mapa de declividade e comparando os resultados com o Google Maps. Para gerar as curvas de nível do município foi empregado o Global Mapper v15 que utiliza como parâmetro o banco de dados do Aster (Advanced Spaceborne Thermal Emission and Reflection Radiometer) Global Digital Elevation Model Version 2, no site contém advertências quanto ao uso por conter anomalias que impedem o seu efetivo emprego em certas aplicações mais detalhadas ou de maior acurácia, mas como se trata de um modelo de estudo da área em primeira instância, pode servir como base para futuros levantamentos mais aprofundados no que se refere a implantação do loteamento. Para uma melhor visualização da área pode-se valer de uma visão tridimensional do município.

Fig 1: Modelo tridimensional da área do perímetro urbano do município.

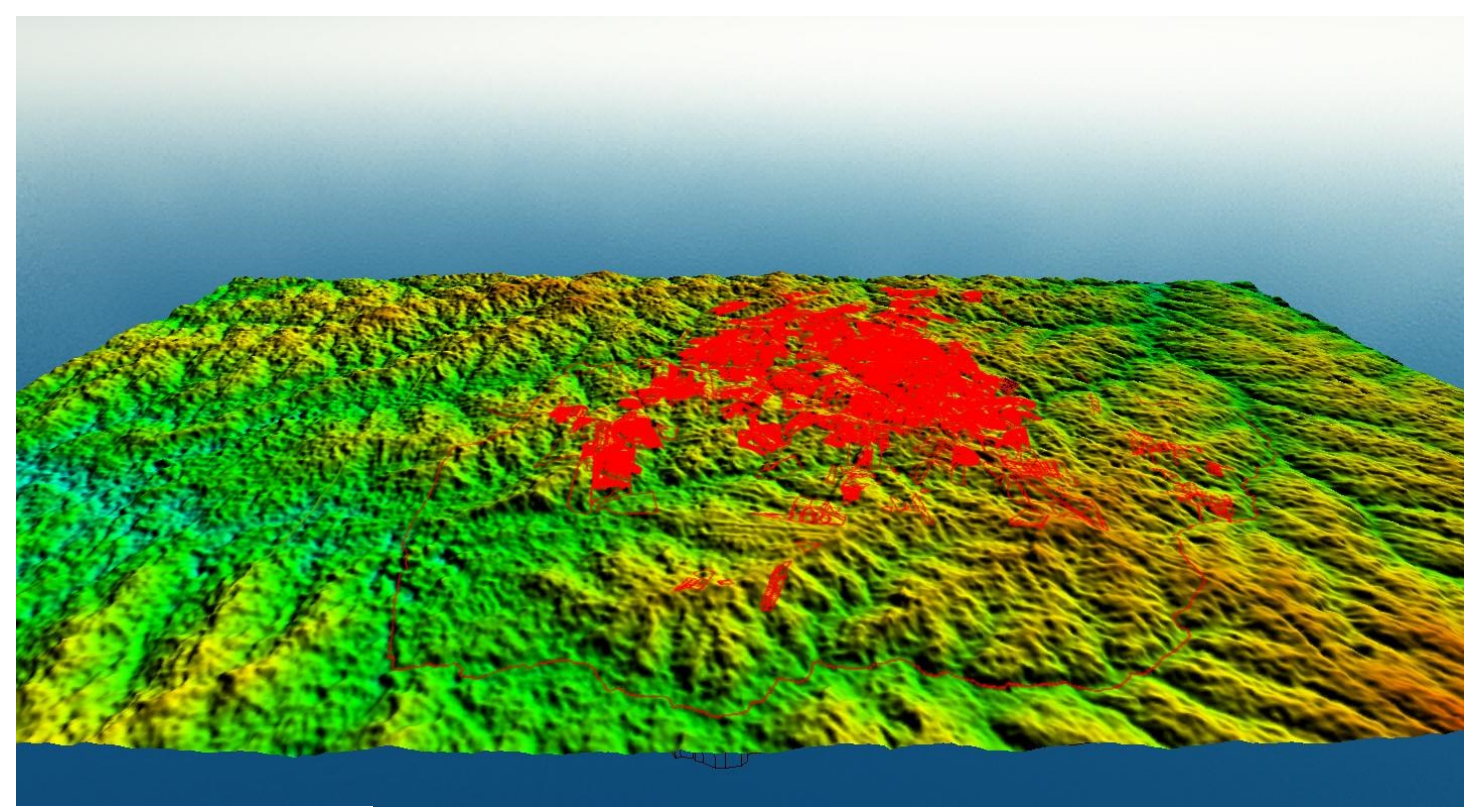

FONTE: ASTER (200-?). Adaptado pelos autores, 2016. 


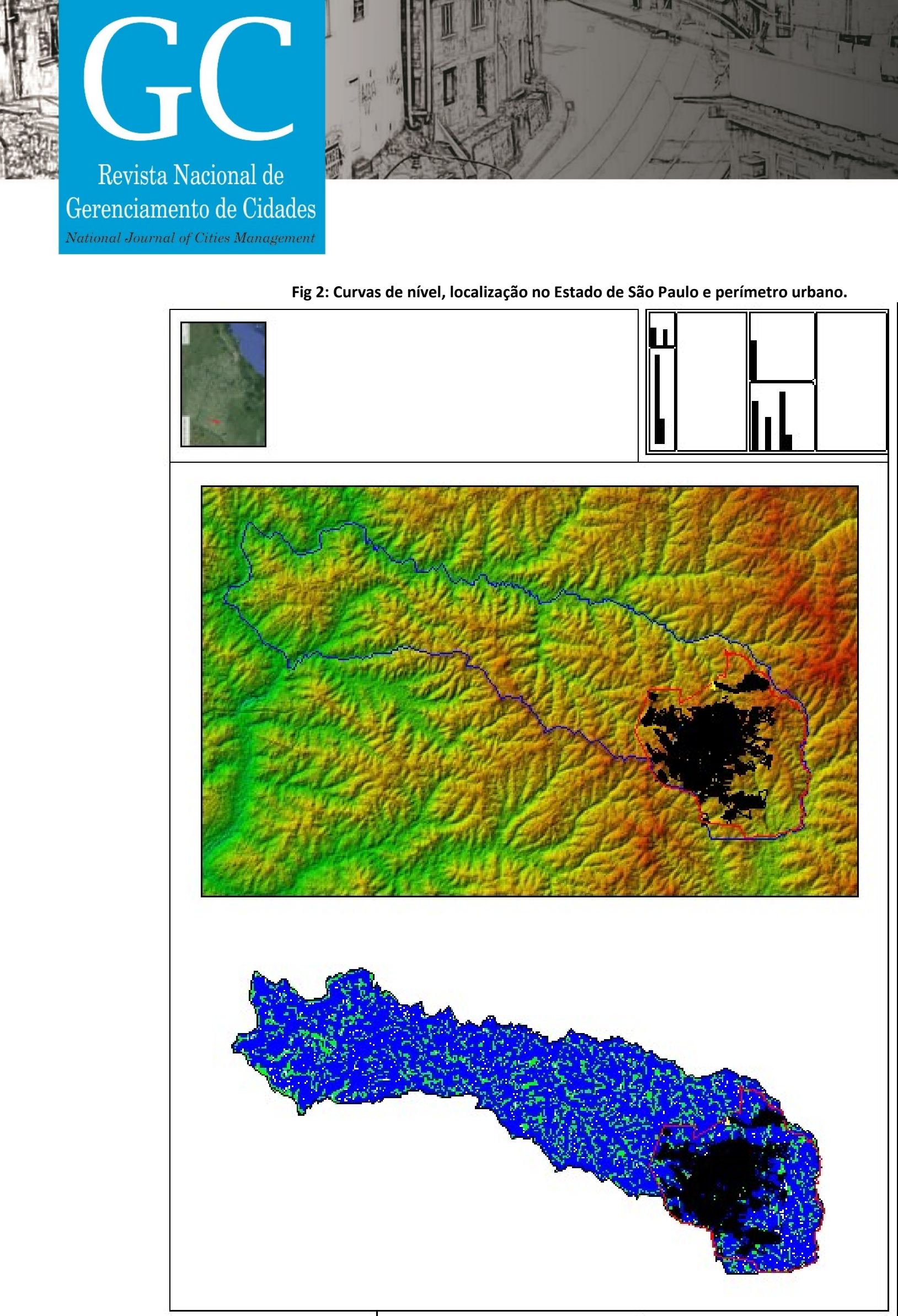

FONTE: ASTER (200-?). Adaptado pelos autores,2016. 


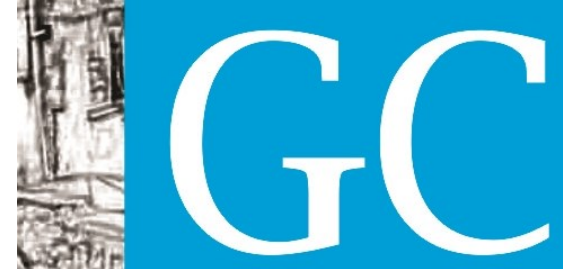

Revista Nacional de

Gerenciamento de Cidades
ISSN 2318-8472

v. 04, n. 25, 2016

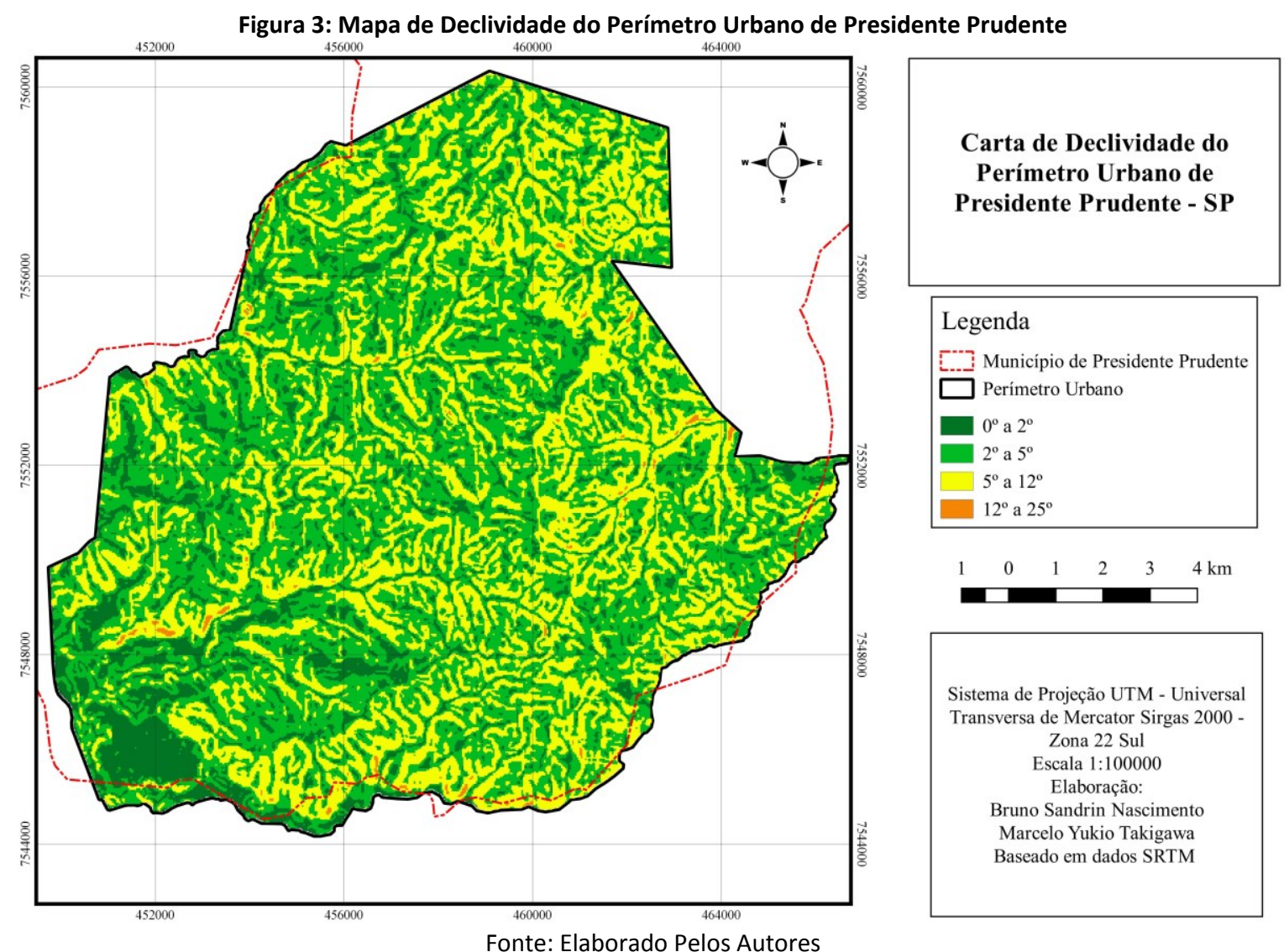


Analisando o mapa e aliando com o sistema viário existente, a área foi escolhida pela sua facilidade de acesso com importantes rodovias para o escoamento da produção, pouca declividade e afastada de grandes aglomerações residenciais. Além disso, procurou-se um espaço que apresentasse pouco ou nenhum elemento hidrográfico, como córregos e rios.

No site do ICEA (Instituto de Controle do Espaço Aéreo), que utiliza o banco de dados climatológicos do Comando da Aeronáutica, pode-se realizar um levantamento da média de direção e velocidade do vento por períodos de tempo determinado. No município de Presidente Prudente a direção predominante é de leste-sudeste. Apesar disso a escolha da área na porção Oeste da cidade, pode ser justificada pelo fato de que em um raio de 2.000 metros, a partir do lote industrial mais externo do loteamento, visualiza-se que há pouca densidade residencial. Em pesquisa ao banco de mapas da Prefeitura Municipal, encontramos 1.203 lotes, sendo o mais próximo a 500 metros de distância.

Fig. 4 Direção do Vento e intensidade.

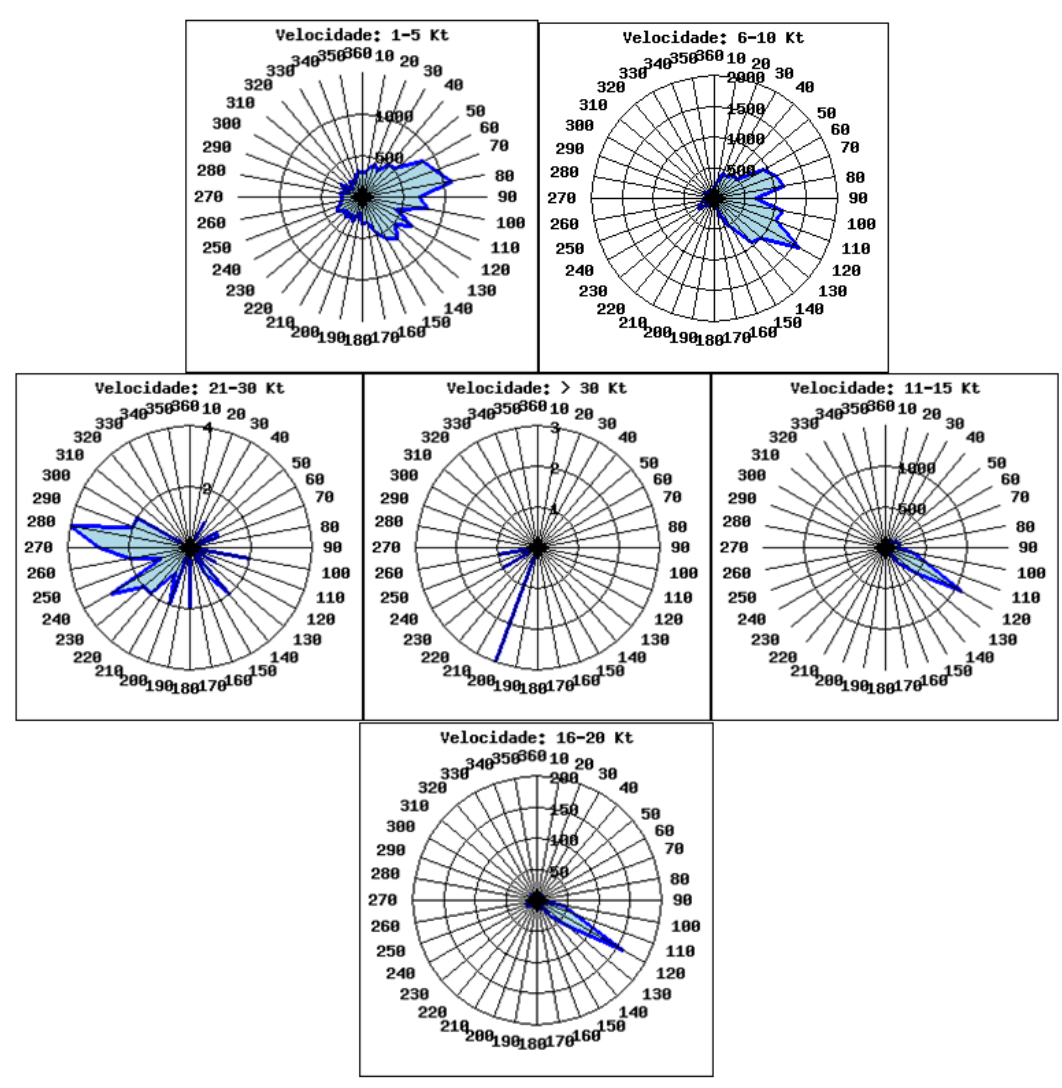

Fonte: ICEA (Instituto de controle do Espaço Aéreo).

A área escolhida localiza-se na parte oeste do município e tem como acesso a Avenida José Campos do Amaral, que possui faixas de rolamento de 10,00 metros, conforme planta de aprovação do Residencial Anitta Tiezzi, e com expansão na altura do Royal Park e Rota do Sol de 16,00 metros no total, permitindo um grande fluxo de veículos. Possui área total de 
$557.548,23 \mathrm{~m}^{2}$ e em sua porção norte apresenta uma área de $32.835,86 \mathrm{~m}^{2}$ de área de preservação.

Consultando o plano diretor, nota-se que parte da área proposta está localizada fora do perímetro urbano e outra está inserida em uma zona de uso predominantemente residencial de média densidade populacional. Nesse caso pode-se propor a alteração da lei do perímetro urbano, alcançando o limite do município com a cidade limítrofe de Álvares Machado. Na região da ZR2 (zona residencial de média densidade populacional, de ocupação horizontal vertical de até dois pavimentos) e ZE9 (zona especial de cemitério municipal) a proposta é o de lotes institucionais, áreas de lazer, áreas verdes e lotes residenciais. Conforme informações prestadas pelo corpo técnico da Prefeitura as chamadas Zonas Especiais herdam as características do zoneamento mais próximo.

Fig. 5 Parâmetros e índices urbanísticos dos zoneamentos.

\begin{tabular}{|c|c|c|c|c|c|c|c|c|c|}
\hline \multirow{6}{*}{ 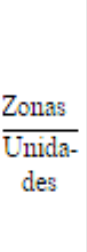 } & \multirow{6}{*}{$\begin{array}{c}\text { Tamanho } \\
\text { Minimo } \\
\text { do lote }\end{array}$} & \multirow{5}{*}{\multicolumn{2}{|c|}{$\begin{array}{c}\begin{array}{c}\text { Frente Minima } \\
\text { do lote }\end{array} \\
\begin{array}{c}\text { Normal } \\
\text { esquina }\end{array} \\
\end{array}$}} & \multirow{6}{*}{$\begin{array}{l}\text { Coeficiente de } \\
\text { Aproveita- } \\
\text { mento } \\
\text { Máximo } \\
\text { Número }\end{array}$} & \multirow{6}{*}{$\begin{array}{c}\text { Taxa de } \\
\text { Ocupação } \\
\text { Máxima } \\
\text { Percentagem }\end{array}$} & \multirow{6}{*}{$\begin{array}{l}\text { Recuo } \\
\text { Frontal } \\
\text { Minimo } \\
\text { Metro } \\
\text { Linear }\end{array}$} & \multirow{6}{*}{$\begin{array}{c}\text { Área minima } \\
\text { de Terreno } \\
\text { por Unidade } \\
\text { Habitacio- } \\
\text { nal } \\
\text { Metro } \\
\text { Quadrado }\end{array}$} & \multirow{6}{*}{$\begin{array}{c}\text { Taxa de } \\
\text { Permeabili- } \\
\text { dade } \\
\text { Minima } \\
\text { Percentagem }\end{array}$} & \multirow{6}{*}{$\begin{array}{l}\text { Gabari-to } \\
\text { de Altura } \\
\text { Máxima }\end{array}$} \\
\hline & & & & & & & & & \\
\hline & & & & & & & & & \\
\hline & & & & & & & & & \\
\hline & & & & & & & & & \\
\hline & & \multicolumn{2}{|c|}{$\overline{\text { Metro Linear }}$} & & & & & & \\
\hline ZR1 & $\begin{array}{c}420 / 250 \\
\text { (11) }\end{array}$ & $\begin{array}{c}14 / 12 \\
(11)\end{array}$ & $\begin{array}{c}19 / 14 \\
(11)\end{array}$ & 1 & 50 & 4 & 420 & $20 / 10(11)$ & $2(8)$ \\
\hline$\overline{\mathrm{ZR} 2}$ & 250 & 12 & 14 & 2 & 70 & 4 & 60 & 10 & $2(8)$ \\
\hline$\overline{\mathrm{ZR} 3}$ & 250 & 12 & 14 & $4(10)$ & 70 & 4 & 20 & 10 & Livte \\
\hline$\overline{Z R 4}$ & 160 & 08 & 12 & 2 & 70 & $4 / 2(9)$ & 60 & 10 & $2(8)$ \\
\hline$\overline{\mathrm{ZCS} 1}$ & 500 & 15 & 19 & $4(10)$ & $80(1) / 70(2)$ & $0(3) / 4(4)$ & 10 & $0(5) / 10(6)$ & Livte \\
\hline $\mathrm{ZCS} 2$ & - & - & - & 4 & $80(1) / 70(2)$ & $0(3) / 4(4)$ & 10 & $0(5) / 10(6)$ & Livte \\
\hline$\overline{\mathrm{ZCS} 3}$ & \multicolumn{9}{|c|}{ Parâmetro da zona envolvente de maior coeficiente de aproveitamento ( 7 ) } \\
\hline$\overline{Z I 1}$ & 500 & 15 & 19 & 2 & 70 & 4 & 20 & 20 & Livre \\
\hline ZI2 & 1000 & 20 & 30 & 2 & 60 & 10 & $\ldots$ & 20 & Livre \\
\hline
\end{tabular}

FONTE: Anexo II da Lei Complementar 153/2008.

$\mathrm{Na}$ área sem zoneamento a proposta é o de ZI1, zona de indústrias não poluitivas. Nesse zoneamento é tolerado a implantação de edificações residenciais, apesar de não ser essa a proposta inicial devido a poluição sonora e atmosférica e o tráfego de veículos pesados que acarretam em transtornos a quem futuramente irá se instalar na área e ao entorno, mas na área em que o zoneamento está definido como residencial, ocorre a obrigação da implantação de residências e áreas de interesse público, tais como praças de lazer, escolas, creches e postos de saúde para atender a população do próprio loteamento e do entorno.

Analisando o Guia de Sustentabilidade da Caixa Econômica Federal (2010) e o mapa de escolas da Prefeitura Municipal de Presidente Prudente, pode-se constatar que para a implantação de um loteamento do tipo residencial na área de estudo, deve-se cumprir com o requisito de uma escola pública de ensino fundamental em um raio máximo de $1,5 \mathrm{Km}$, pois as mais próximas não atingem a área mínima de cobertura do loteamento mais próximo que conta com 537 lotes. 


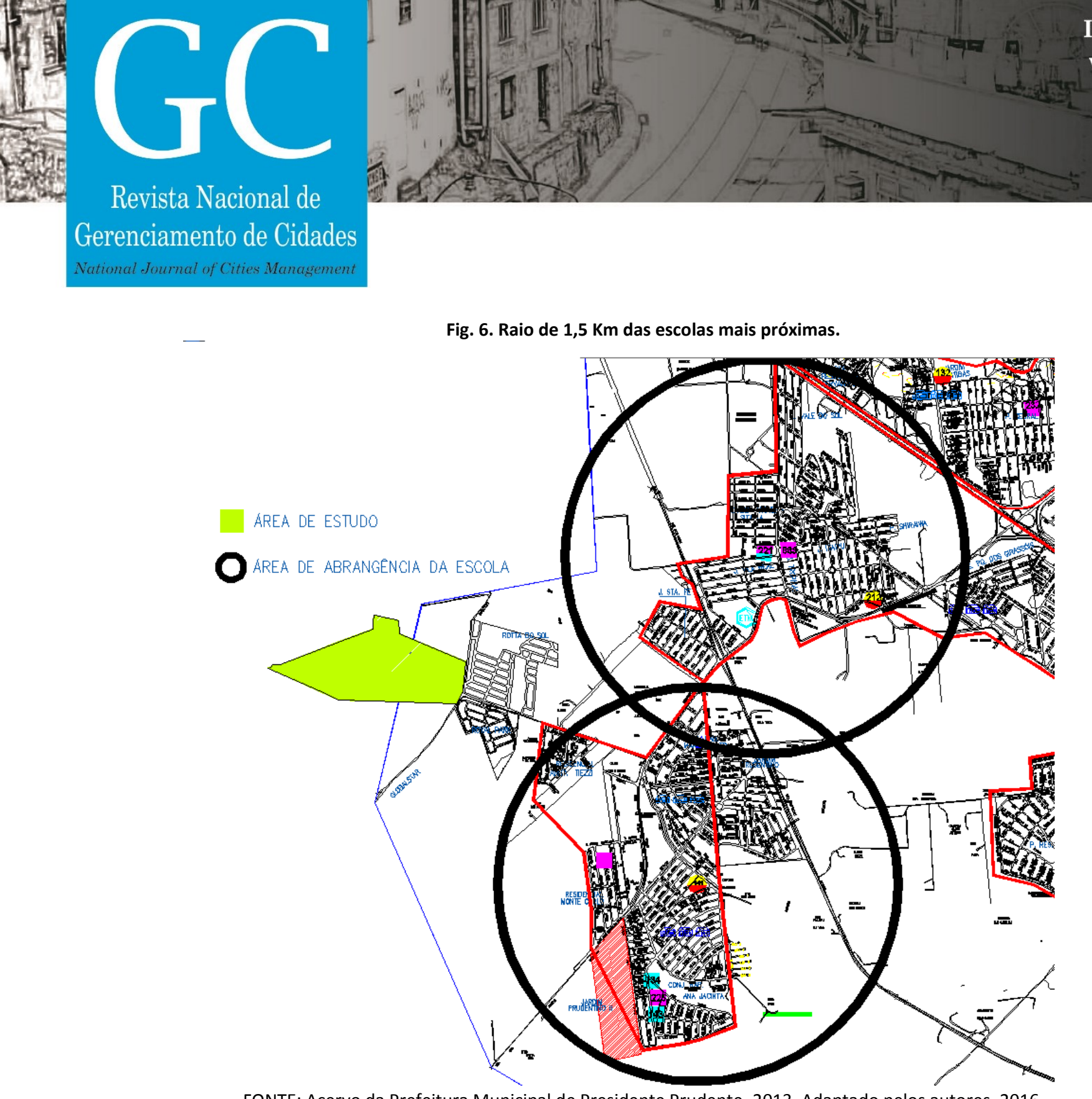

\section{Revista Nacional de}

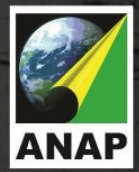

Gerenciamento de Cidades

FONTE: Acervo da Prefeitura Municipal de Presidente Prudente, 2013. Adaptado pelos autores, 2016.

O Plano Diretor, a Lei do Sistema Viário e Lei de Uso e Ocupação do Solo municipais não delimitam de forma clara os parâmetros para a implantação de novos empreendimentos, fazendo com que sejam muito vagas nesse sentido, dificultando o estudo e possibilitando essa abertura para requisitar a alteração requerida.

A implantação de um novo distrito industrial se faz necessário devido a grande procura por lotes no ultimo aprovado, ainda em fase de implantação, e a grande ocupação nos antigos. A parte ambiental deve ser disciplinada com alterações no Plano Diretor ou por leis específicas que visem a sua proteção e manutenção.

Baseando-se no levantamento de LIMA (1980), que buscou na literatura bases para a implantação de cinturão verde para minimizar os efeitos poluitivos e sonoros em áreas industriais e seguindo a legislação vigente propõe-se a criação de um cinturão verde de 30,00 de largura em torno do loteamento industrial para diminuir a poluição sonora e minimizar os efeitos da poluição atmosférica. Para JENSEN et al (1976) a vegetação absorve, através das trocas gasosas, os poluentes presentes no ar denominando isto como efeito ativo. No mesmo estudo o autor classifica como efeito passivo a formação de uma barreira física, pelas árvores, das correntes de ar e o transporte de partículas nocivas. 


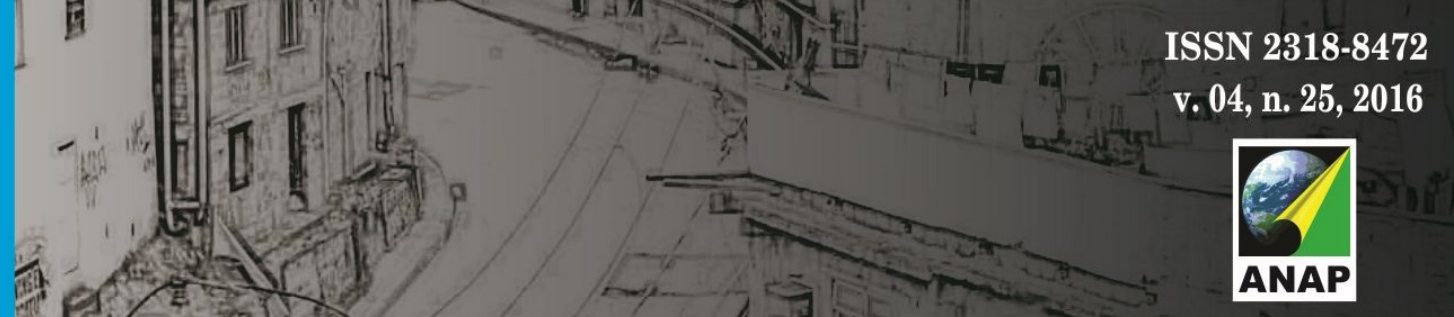

Revista Nacional de Gerenciamento de Cidades

SMITH (1974) estabelece relação entre a efetiva proteção das florestas na retenção e absorção dos contaminantes atmosféricos em baixa concentração para não afetar a saúde das plantas e demonstram que em altos níveis de poluição a floresta tem seu efeito de filtragem diminuído. STRAIGHT (2011) estabelece relação entre barreiras de vegetação para amenizar a incidência do efeito da poluição sonora sobre as áreas próximas.

TOWNSEND (2011) realizou pesquisas no sentido de correlacionar as árvores com ilhas de calor, espaço verde e aumento na qualidade de vida (física e mental). As cidades devem aliar projetos arquitetônicos com a paisagem em que está inserido.

Deve-se consultar corpo técnico especializado em busca das espécies resistentes ao diferente tipo de poluentes atmosféricos derivados das indústrias de transformação, pois o plantio de espécies sensíveis leva a perda de efetividade, lesões e mortes das plantas.

\section{CONCLUSÃO}

O município de Presidente Prudente, apesar de ser considerada como uma sede regional na região oeste do Estado de São Paulo, não conta com o aval da CETESB para a realização de licenciamento ambiental, devido a falta de corpo técnico na Prefeitura Municipal, remetendo a obrigação para o órgão estadual. A legislação municipal pode até servir como base para uma orientação inicial da implantação do loteamento, mas ela é elaborada de forma genérica e sem definições pontuais para o desenvolvimento do trabalho, deixando espaço para adaptações que podem levar ao prejuízo do meio ambiente e da população em geral.

O planejamento da área não é somente o levantamento da região selecionada, mas uma busca por fatores que possam limitar geograficamente a sua implantação, nível de aceitação por parte dos interessados, sistema viário, legislação de incentivos fiscais para atrair e fixar as empresas. A implantação pode ser efetuada em fases, conforme a necessidade e interesse por parte do município, sempre verificando a dotação orçamentária e a procura por parte das empresas.

No caso de haver interesse por parte da loteadora e com a anuência do município, parte da área que seria reservada para as áreas institucional e de lazer pode ser compensada em outros locais. Sendo que pode ocorrer a compra de glebas ou ressarcimento ao erário, após elaboração de laudos técnicos de avaliação. 


\section{REFERÊNCIAS BIBLIOGRÁFICAS}

CHIAVENATO, Idalberto; SAPIRO, Arão. Planejamento Estratégico. 12. ed. Rio de Janeiro: Elsevier Editora Ltda, 2004. 413 p.

MARRONE, Patricia. A importância das indústrias para o Estado. 2012. Disponível em: <http://economia.estadao.com.br/noticias/geral,a-importancia-da-industria-para-os-estados-imp-,910993>. Acesso em: 24 abr. 2016.

MARTINS, José Pio. A importância da indústria. 2013. Disponível em: <http://www.gazetadopovo.com.br/opiniao/artigos/a-importancia-da-industria-c2t8xbjdnw63it4y2maosp26m>. Acesso em: 24 abr. 2016.

Carta IEDI n525: Por Que a Indústria É Relevante Para o Desenvolvimento Brasileiro?. 2012. Disponível em: <http://www.iedi.org.br/cartas/carta_iedi_n_525.html>. Acesso em: 24 abr. 2016.

BELLUZZO, Luiz Gonzaga; ALMEIDA, Julio Sergio G. A importância da indústria. 2012. Disponível em: <http://www.cartamaior.com.br/?/Editoria/Economia/A-importancia-da-Industria/7/25035>. Acesso em: 24 abr. 2016.

PULIDO, Anelise Santos; SHINTATE, Paula Tamy; RIZK, Maria Cristina.Diagnóstico Ambiental de Empreendimentos do Distrito Industrial Antônio Crepaldi - Presidente Prudente/SP. 2011. 124 f. TCC (Graduação) - Curso de Engenharia Ambiental, Departamento de Planejamento, Urbanismo e Ambiente, Universidade Estadual Paulista "Julio de Mesquita Filho", Presidente Prudente, 2011. Disponível em: <http://repositorio.unesp.br/bitstream/handle/11449/120674/pulido_as_tcc_prud.pdf>. Acesso em: 24 abr. 2016.

FONSECA, Stephanie. Prefeitura proíbe entrada de coletores no aterro de Presidente Prudente. 2015. Disponível em: <http://g1.globo.com/sp/presidente-prudente-regiao/noticia/2015/06/prefeitura-proibe-entrada-de-coletoresno-aterro-de-presidente-prudente.html>. Acesso em: 24 abr. 2016.

AMORIM, Margarete Cristiane de Costa Trindade et al. Características das ilhas de calor em cidades de porte médio: exemplos de Presidente Prudente (Brasil) e Rennes (França). 2009. Disponível em: <https://confins.revues.org/6070?lang=pt\#ftn1>. Acesso em: 24 abr. 2016.

AMORIM, Margarete Cristiane de Costa Trindade. O clima urbano de Presidente Prudente /SP, Tese Doutorado em Geografia, Faculdade de Filosofia, Letras e Ciências Humanas, Universidade de São Paulo.São Paulo, 2000. 374p.

PRESIDENTE PRUDENTE / SP. SECRETARIA MUNICIPAL DE COMUNICAÇÃO. . Prefeito entrega mais 23 lotes do Distrito Industrial 'Achilles Ligabô', na Ângelo Rena. 2016. Disponível em: <http://www.presidenteprudente.sp.gov.br/site/noticias.xhtml?cod=32340>. Acesso em: 24 abr. 2016.

SUDO H., Leal A. C., "Aspectos geomorfológicos e impactos ambientais da ocupação dos fundos de vales em Presidente Prudente-SP", Revista Natureza, Uberlândia, p.362-367, 1996.

LIMA, Walter de Paula. As Florestas e a Poluição do Ar. Piracicaba: IPEF - Instituto de Pesquisas e Estudos Florestais - Dep. de Silvicultura da E.S.A.L.Q. - USP, 1980. 41 p.

JENSEN, K.F. et al. Pollution Responses. In: MIKSCHE, J.P. Modern Methods in Forest Genetics. New York, Springer Verlag, 1976. Chapter. 9. p. 189-216. Disponível em:< http://link.springer.com/chapter/10.1007/978-3-662-125236_9\#page-1>. Acesso em: 25 abr. 2016.

SMITH, William H. Air pollution-effects on the structure and function of the temperate forest ecosystem. Environmental Pollution, Amsterdam, v. 6, n. 2, p.111-129, fev. 1974. 
